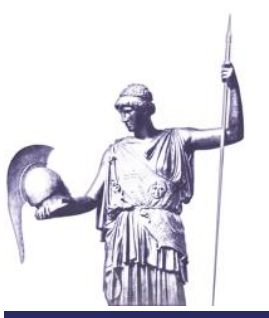

Editorial
Connections: The Quarterly Journal

ISSN 1812-1098, e-ISSN 1812-2973

\title{
Emerging Security Challenges: An Introduction
}

\section{Detlef Puhl}

\author{
Emerging Security Challenges Division, NATO International Staff
}

The security landscape at the beginning of the $21^{\text {st }}$ century is a fluid and dynamic one, characterized by developments in technology, in weapons and communications systems as well as by shifts in the international political landscape and organizational structures of non-state actors posing serious and imminent threats to national and international security. Within this environment NATO finds itself at a crossroads. Its Strategic Concept, adopted in Lisbon in November 2010, marks the beginning of its adjustment to this new reality, reflecting a security environment with effects far beyond NATO and its partners - an environment which will see the fundamental global shifts continue in the coming years: In the global distribution of power, including revisionist activities in our immediate neighborhood and a fundamental challenge to our rules-based international order by mainly radical islamist organizations; in demographics; in economics; in technology; in the environment. Faced by such very different global challenges to our security, NATO must seek to maintain its cohesion and develop a broader notion of transatlantic security and enhance its relevance in meeting modern day threats and challenges.

In the face of many non-traditional, mostly non-military security challenges, which affect Allies in different ways, the Alliance needs to reaffirm and enhance its cohesion both within the organization and with its Partners and beyond. It needs to develop policies and activities if they don't want to be overwhelmed by those new challenges. In order to fulfill this task, Allies need new and more expertise about those challenges, within the organization and shared by all Allies and Partners. They need to raise and maintain 
awareness of them and actively cooperate more with outside actors. In this regard, neutral and non-aligned nations and their seasoned experience in the exercise of soft power have much to offer.

To this end, the Partnership for Peace Consortium has created its Emerging Security Challenges Working Group to promote reflection on a number of very fundamental questions:

- What exactly are "Emerging Security Challenges" which NATO deals with in a specific division of its International Staff, created in 2010?

- What role is there to play for the military in addressing them?

- How do we need to be organized to meet those challenges?

- What can the Alliance and its Partners, in cooperation with neutral and non-aligned nations and others, do to help guide this process?

- What impact does addressing these challenges collectively have on the way in which we interact internationally?

- How do we need to educate and train our staff and leaders so they are able to cooperate intelligently in an ever more complex and interconnected security environment?

In effect, we need to think, talk, discuss collectively about an emerging security environment which is very different from what we are used to. This is true for all of our countries, for the Alliance as an organization, and for the whole international community. This environment will keep changing in sometimes surprising and unexpected ways and we don't know what comes next. It will be critical for Allies and their Partners to find compatible, if not similar or even common answers to these challenges. Some consider NATO to be a useful and proven framework and tool to commonly address such challenges to our security; others prefer to rely on national capabilities and bilateral cooperation, charging NATO with providing the indispensable back-up to territorial security.

The Emerging Security Challenges Working Group has discussed many of these questions in the six workshops it has held so far. Its ambition is to examine and raise awareness of emerging technologies and their impact on security policy. It also strives to foster engagement between NATO nations and Partner nations - offering a platform for discussions among NATO and partner experts. It finally seeks to develop curricula for education of military and civilian leadership who have to deal with these complex issues.

This special edition of "Connections" presents an overview of some of the topics which the Working Group considers to constitute "emerging se- 
curity challenges." This list can and will be completed over time, as technological innovation and political developments in the international community continue to evolve.

The authors of the first five papers in this edition have all presented their thoughts on the issue to the Emerging Security Challenges Working Group and spurred interesting discussions in different workshops, which resulted in a number of Policy Papers and Background Papers published by the PfP Consortium. Here, they all address the question of why policy makers in the security field should care about the particular issue, what are fundamental technological trends, and potential security implications to policy making in our nations and within NATO. Authors from outside the Working Group complement these reflections, focusing on particular issues of what is now called "hybrid warfare" in the context of the Russian-Ukrainian conflict.

The Co-Chairs thank all the authors and contributors to what will continue to constitute a relevant and fascinating debate on international security policy.

\section{About the author}

Since 2011, Dr. Detlef Puhl serves as Senior Advisor for Strategic Communication to the Assistant Secretary General of NATO for Emerging Security Challenges, delegated from the German Ministry of Defense. Previously, from 2008 to 2011, he was Assistant Director at the "Délégation aux Affaires Stratégiques," the Policy Planning Staff of the French Ministry of Defense. Prior to that, from 2002 to 2008, as Associate Dean of the "College for International and Security Studies" at the George C. Marshall Center in Garmisch-Partenkirchen, he worked very closely with the US Department of Defense and US European Command, as well as representatives from Central and Eastern Europe and Eurasia. From 1998 to 2001, he was Director of Press and Information and Spokesman of the German Ministry of Defense. Until then, Dr. Puhl had worked for many years as military and security policy correspondent of the "Stuttgarter Zeitung" in Bonn and Stuttgart.

E-mail: detlef.puhl@gmx.net 